\title{
Myoepithelioma of Soft Palate: A Case Report
}

\author{
Radha Baral, ${ }^{1}$ Bidhata Ojha, ${ }^{1}$ Dipshikha Bajracharya, ${ }^{1}$ Sumit Singh ${ }^{2}$ \\ ${ }^{1}$ Department of Oral Pathology, ${ }^{2}$ Department of Oral Surgery, Kantipur Dental College, Basundhara, Kathmandu, \\ Nepal.
}

\begin{abstract}
Myoepithelioms are rare benign salivary gland tumors representing $1-1.5 \%$ of all salivary gland tumors. It was once considered to be one end of the histologic spectrum of pleomorphic adenoma (PA), but myoepitheliomas today are believed to be distinct entity. Herein we report a case of myoepithelioma in a 49 years old female patient with the history of swelling in the soft and hard palate. The diagnosis was made on the basis of histopathological findings and immunohistochemical report.
\end{abstract}

Keywords: myoepithelioma; palate; swelling.

\section{INTRODUCTION}

Myoepitheliomas are rare benign neoplasms of salivary glands. They represent $1-1.5 \%$ of all salivary gland tumors. ${ }^{1}$ They usually occur in the parotid gland and infrequently in minor salivary glands. $^{1,2}$ It was once considered to be one end of the histologic spectrum of pleomorphic adenoma (PA), but myoepitheliomas today are believed to be distinct entity. ${ }^{3}$ Myoepithelioma are composed of exclusively sheets, islands or cords of cells with myoepithelial differentiation that may exhibit spindle, plasmacytoid, epithelioid or clear cytoplasmic features. ${ }^{3}$

\section{CASE REPORT}

A 49 years old female patient reported with swelling in the left half of soft palate region since 2 years. Swelling was small on onset but gradually increased in sized to present. Patient had difficulty

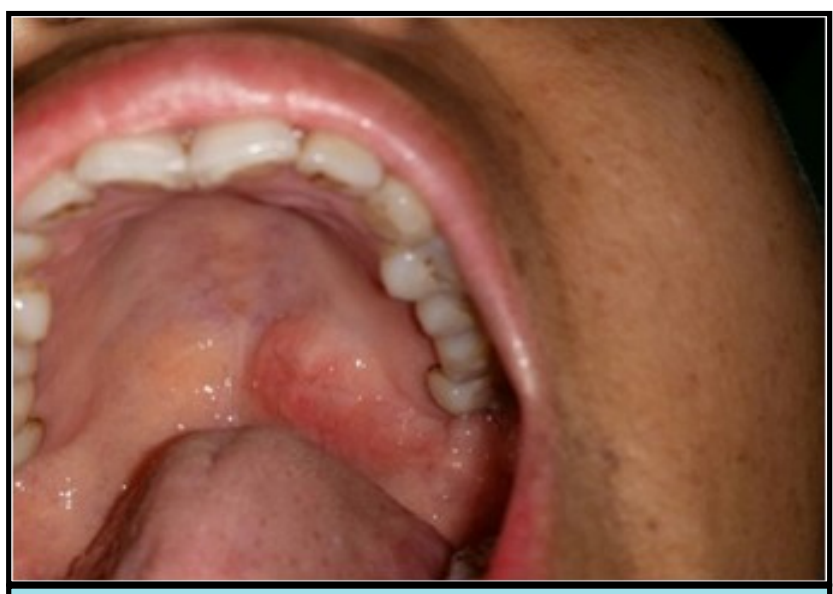

Figure 1. Clinical presentation showing swelling on the left palatal region. in swallowing. Personal history of the patient was negative. The swelling was about $2 \mathrm{~cm} \times 2 \mathrm{~cm}$ in size on the left side of the palate extending anteriorly to second molar and posteriorly to the soft palate involving entire soft palate. The overlying mucosa was slightly erythematous. There was no ulceration of overlying mucosa (Figure 1). On palpation the lesion was firm and non tender. Based on the clinical findings differential diagnosis of pleomorphic adenoma, adenoid cystic carcinoma and low grade mucoepidermoid carcinoma was made and incisional biopsy of the lesion was performed.

On histopathological examination incisional biopsy revealed tumor mass composed of sheets of tumor cells with plasmacytoid differentiation with dark basophilic eccentric nuclei and eosinophilic cytoplasm. The stroma was hyalinized and very few ductal structures could be appreciated. Immunohistochemical findings revealed that tumor demonstrated strong positivity for S-100 protein and strong patchy positivity for smooth muscle actin (SMA) and cytokeratin. Glial fibrillary acidic protein (GFAP) and calponin were focal positive (Figure 2). High molecular weight cytokeratin (HMWCK) and EMA revealed focal positivity around ductal structures. Based on both histopathological and immunohistochemical findings diagnosis of myoepithelioma was made.

Excisional biopsy of the lesion was performed and we received a single piece of well encapsulated soft tissue mass brownish in color firm in consistency measuring $1.5 \mathrm{~cm} \times 2.4 \mathrm{~cm}$ in size. The cut surface

Correspondence: Dr. Dipshikha Bajracharya, Department of Oral Pathology, Kantipur Dental College, Basundhara, Kathmandu, Nepal. Email: drdipshikhabaj@gmail.com. Phone: +977-9860536501. DOI:10.3126/jcmsn.v14i4.21969. Article received: 2018-12-04. Article accepted:2018-12-20. 


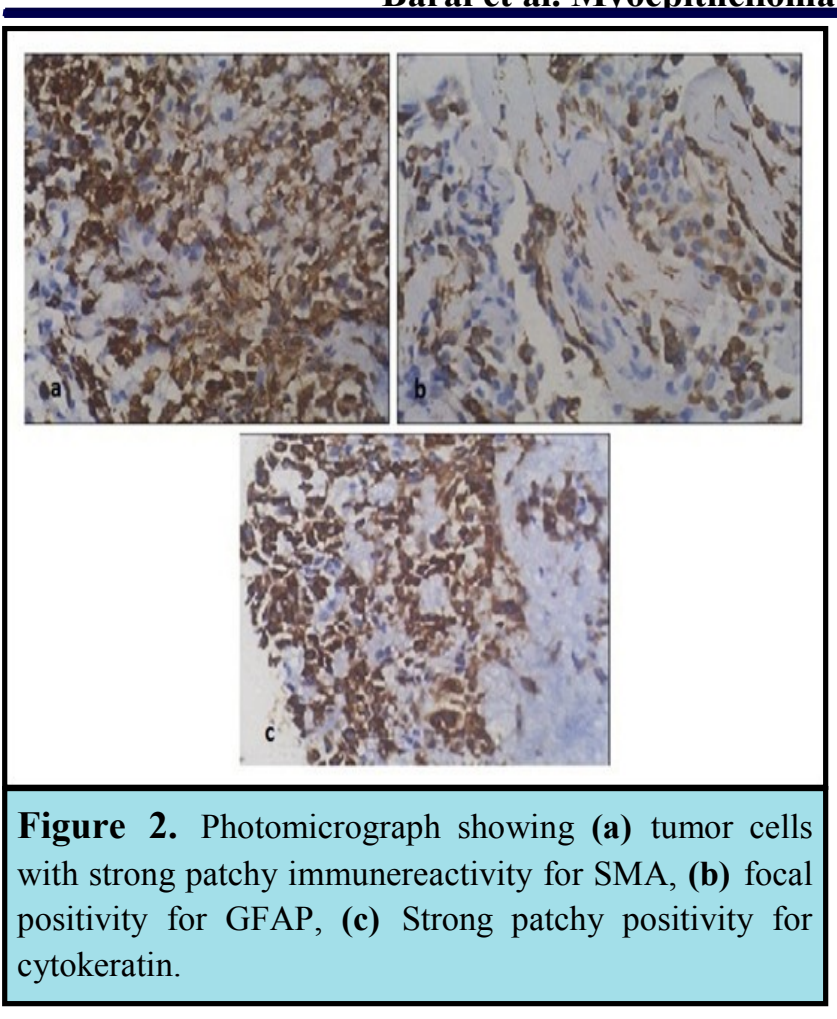

showed uniform white area enclosed within a capsule. On histopathological examination tumor mass was well encapsulated with tumor cells infiltrating into the capsule. Higher magnification revealed tumor sheets of plasmacytoid cells with dark basophilic eccentric nuclei and eosinophillic cytoplasm (Figure 3). Mitotic figures were not evident. Tumor stroma was hyalinized with no chordromyxoid and osteoid features. Based on clinical, histopathological and

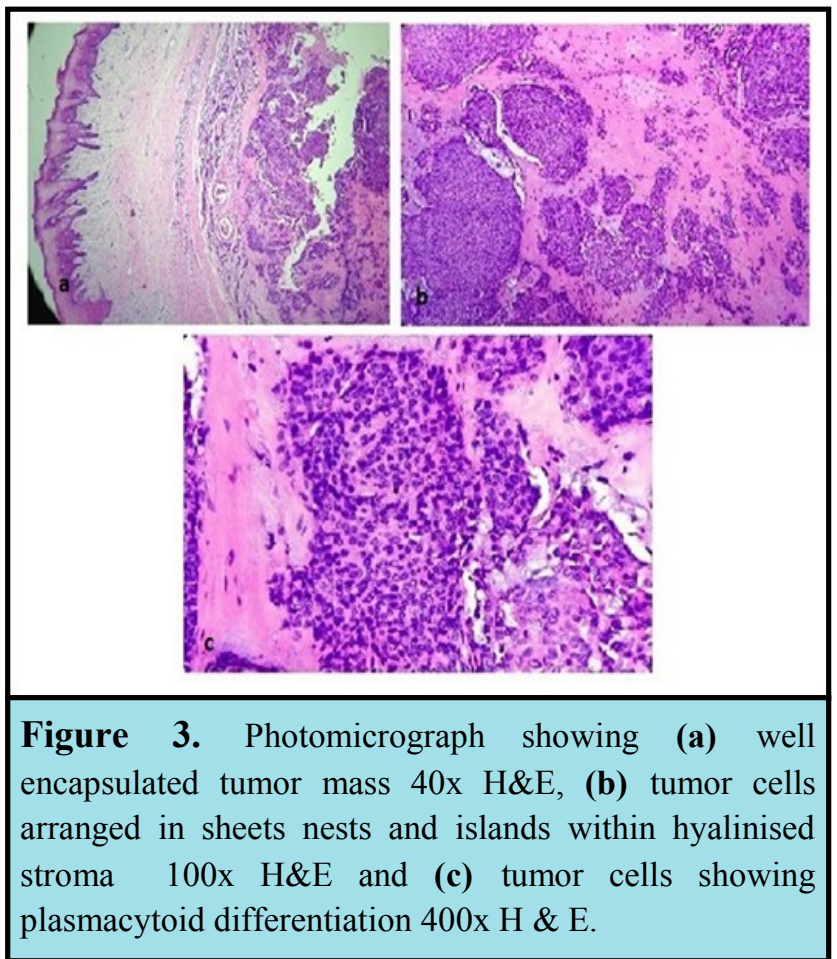

immunohistochemical findings, final diagnosis of myoepithelioma was made.

\section{DISCUSSION}

Myoepithelioma are benign salivary gland tumor with cells with predominant myoepithelial differentiation. It is a rare benign mass arising from neoplastic myoepithelial or basket cells, which are found between the basement membrane and the basal plasma membrane of acinar cells. ${ }^{4}$ Majority of these tumors arise in parotid gland followed by minor salivary glands of palate. The tumor does not show any unique clinicopathologic features that is different from other benign salivary gland tumors but is believed to have more aggressive behaviour. ${ }^{5}$ Males and females are affected with equal frequency. The patient age range is 9-85 years (mean: 44 years), with an incidence peak in the third decade of life. ${ }^{6}$ Myoepitheliomas are wellcircumscribed solid tumours. They typically present as painless slow growing firm masses. Clinically they are indistinguishable from pleomorphic ademoma. $^{5,6}$

Parotid myoepitheliomas are usually encapsulated, whereas those arising in the minor salivary glands may not demonstrate a capsule similar to present case. $^{5,7}$ Histopathologically, myoepithelial tumor cells can show four morphologies spindle (elongated to ovoid), epithelioid (round to polygonal), hyaline (plasmacytoid) or clear cells. These tumor cells can be arranged in various architectural patterns like non myxoid (solid), myxoid (pleomorphic adenoma like), reticular (canalicular like) and mixed. ${ }^{8}$ The histological type of the tumor is related to its location and behavior. Particularly, it seems that spindle-cell and clear-cell type occur more often in parotid glands, while plasmacytoid type occurs more often intraorally, especially in the minor salivary glands of the palate which was also seen in our case. ${ }^{9}$ Despite the fact that this tumor demonstrate intense hyalinization of the connective tissue as well as foci of myxoid changes, there is no evidence of chondroid or osteoid tissue which is similar to our study. ${ }^{3}$

Conflicting results have been obtained on immunostains of myoepitheliomas. The most consistent were the positive staining for cytokeratin, S-100, and SMA, whereas vimentin and Glial fibrillary acidic protein (GFAP), calponin expressions vary. In this present case where tumor demonstrated strong positivity for S-100 protein and strong patchy positivity for smooth muscle actin (SMA) and cytokeratin while GFAP and 
calponin were focal positive. Positive immunoreactivity for pancytokeratin in conjunction with one or more myoepithelial markers may be required for the diagnosis of myoepithelioma which was present in our case. ${ }^{6,10} \mathrm{Ki}-67$ labeling index of more than $10 \%$ in $\mathrm{ME}$ is highly suggestive of malignant biological behavior. ${ }^{1,9} \mathrm{Ki}-67$ labeling index in the present case was only $1 \%$ ruling out possibility of myoepithelial carcinoma. Hence, based on histopathological evaluation and immunohistochemical confirmation of the myoepithelial origin of the tumor cell diagnosis of myoepithelima was given.

\section{CONCLUSION}

Myoepithelioma are benign tumor of salivary gland presenting as a slow growing mass. Careful histopathological examination along with immunohistochemical analysis helps to distinguish this tumor from other salivary gland neoplasm especially from pleomorphic adenoma.

Disclaimer: This case report was presented on International Dental congress Nepal 2017 on $12^{\text {th }}$ November 2017.

\section{REFERENCES}

1. Souliou CE, Tzermpos F, Argyris P, Tosios K. Plazmacitoidni mioepiteliom tvrdog nepca: prikaz slučaja Plasmacytoid Myoepithelioma of the Hard Palate : Case Report. Acta Stomatol Croat. 2017;51 (2):152-6.

2. Yogee A, Choudhary R, Mathur N, Bhuie H. Myoepithelioma of Soft Palate: A Case Report and Review of Literature. Otorhinolaryngol Clin An Int J. 2016;8(1):32-4.

3. Santos EP, Cavalcante DRR, Melo AUC, Pereira JC, Gomes MZ, Lc R. Plasmacytoid myoepithelioma of minor salivary glands : report of case with emphasis in the immunohistochemical findings. Head Face Med. 2011;7(24):1-6.

4. Weitzel M, Cohn JE, Spector H. Case Report Myoepithelioma of the Parotid Gland: A Case Report with Review of the Literature and Classic Histopathology. Case Rep Otolaryngol. 2017;1-4.

5. Sanjai K, Keshavaiah R, Kumar H, Jayaram S.
Myoepithelioma of hard palate : A case report. J Med Radiol Pathol Surg. 2017;4:18-21.

6. Kapoor A, Rajput PS, Bagri PK, Beniwal S, Kumar $\mathrm{V}$, Kumar HS. Myoepithelioma of parotid: A case report and review of literature. J Oral Res Rev. 2014;6(2):1-4.

7. Gore CR, Panicker NK, Chandanwale SS, Singh BK. Myoepithelioma of minor salivary glands - A diagnostic challenge: Report of three cases with varied histomorphology. J Oral Maxillofac Pathol. 2013;17(2):257-60.

8. Palaskar SJ, Kathuriya PT, Deshmukh SD, Nagpal DJ. Myoepithelioma of minor salivary gland. J Oral Maxillofac Pathol. 2014;18(2):324-6.

9. Zormpa MT, Sarigelou AS, Kolokotronis AE. Plasmacytoid Myoepithelioma of the Palate: Case Report. Head Neck Pathol. 2011;5:154-8.

10. Barnes L. Surgical pathology of the head and neck. Informa healthcare; 2009.

Citation: Baral R, Ojha B, Bajracharya D, Singh S. Myoepithelioma of Soft Palate: A Case Report. JCMS Nepal. 2018;14(4):225-7. 